ELORE (ISSN 1456-3010), vol. 15 - 2/2008.

Julkaisija: Suomen Kansantietouden Tutkijain Seura ry.

[http://www.elore.fi/arkisto/2_08/kov2_08.pdf]

\title{
KARHUPROFESSORIN JÄÄHYVÄISET YLIOPISTOLLE Haastattelussa Juha Pentikäinen
}

\author{
Marjo Kovanen
}

Yksi aikakausi päättyi tämän vuoden maaliskuussa, kun Helsingin yliopiston uskontotieteen laitoksen ensimmäinen ja pitkäaikaisin professori Juha Yrjänä Pentikäinen (synt. 26.2.1940 Rantsilassa) jäi virastaan eläkkeelle.

Pohjois-Pohjanmaalla syntyneen Juha Pentikäisen isä oli kirkkoherra. Lapsuutensa ja nuoruutensa Pentikäinen vietti Haapajärven pappilassa. Yliopistouransa lisäksi tämä seitsemän lapsen isä on toiminut myös politiikan parissa. Kunnallispolitiikassa vaikuttamisen lisäksi hän on kunnostautunut Keskustan varapuheenjohtajana 1980-luvulla. Juha Pentikäinen seurasi edeltäjiensä Kaarle Krohnin, Uno Harvan ja Martti Haavion jalanjälkiä kansanuskon tutkijaksi. Hänen tieteellisen tuotantonsa merkittävimpiin tutkimuksiin kuuluvat väitöskirjan The Nordic Dead Child Tradition (1968) lisäksi Marina Takalon uskonto (1971) sekä suomalaista kuolemakulttuuria luodannut Suomalaisen läbtö (1990). Tärkeitä teoksia hänen urallaan ovat olleet myös Kalevalan mytologia (1987), Saamelaiset. Pohjoisen kansan mytologia (1995) ja

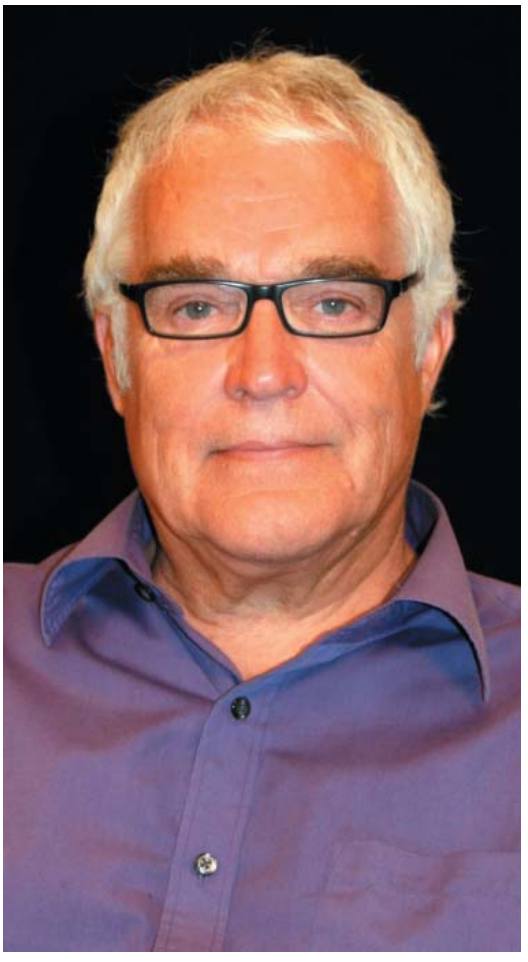

Kuva Vesa Tuisku Samaanit. Pohjoisten kansojen elämäntaistelu. (1998).

Tapasin juuri Turkista palanneen professorin Helsingin Katajanokalla. Eläkkeelle jääminen ei ole suinkaan merkinnyt tuotteliaan tutkijan jäämistä laakereilleen lepäämään, eikä Turkin matkakaan mikään lomareissu ollut, siellä hän nimittäin oli järjestämässä tulevaa sauna-näyttelyä. Tapaamisestamme Pentikäinen riensi suoraan Rovaniemen lentokoneeseen ja seuraavaksi olikin vuorossa Saksan matka - varsin kiireinen eläkeläinen siis. 


\title{
JÄÄHYVÄISET ALMA MATERILLE
}

Helsingin yliopistossa järjestettiin 29.2.2008 jäähyväisluento virkansa jättävälle professorille. Oppiaineen ensimmäinen ordinarius totesi täydelle salille jättävänsä alma materinsa liikuttuneena: "Olen onnellinen siitä, että pitkä rupeama on tullut täytetyksi." Tunnelmiaan eläkkeelle jäämisestään hän luonnehti haastattelun yhteydessä näin:

\begin{abstract}
Koska olen voimissani, haluan hoitaa asioita, jotka ovat jääneet odottamaan rauhallisempia aikoja. Aikaa mieluisille asioille jää enemmän, kun en ole enää vastuussa yliopiston virasta ja sen mukanaan tuomista velvollisunksista. Voin ottaa rennosti ja aikaa jää harrastuksille, kuten bïhtämiselle ja nimiselle. Kaipaan rauhaa ja kiireettömänpää elämäntapaa. Olenkin päättänyt elää ajassa ja pyrin olemaan mabdollisimman vähän sidoksissa kelloon.
\end{abstract}

Kiireisen yliopistoelämän jälkeen rauhalliseen elämänrytmiin mieltynyttä akateemista eläkeläistä ei kuitenkaan toimettomuus uhkaa. Tällä hetkellä Pentikäisen päivät ja viikot täyttää hänelle läheinen projekti:
Bolognassa pidettävä etnografinen näyttely tarjoaa puubaa. Ensimmäinen tehtävä on näyttelyn avaaminen. On bienoa, että näyttely on maailman vanbimmassa yliopis- tossa. Minun etnografinen kokoelmani on sijoitettu luonnontieteellisen kokoelman lomaan. On byvin jublallinen betki tuoda shamaanit ja karbut tällaiseen museoon. On myös todella hienoa, että maailman vanhin ja maailman pohjoisin yliopisto tekevät tällaista ybteistyötä.

Näyttelyjen järjestäminen ja kokoaminen eivät toki ole Juha Pentikäiselle mitään uutta, vaan hän on ollut näyttelyprojekteissa mukana ennenkin. Monet varmasti muistavat neljä vuotta sitten Suomen kierroksensa aloittaneen Karbun kannoilla -näyttelyn, joka rakentui Juha Pentikäisen kokoelmille ja kenttätyökokemuksille Siperiassa. Näyttelynsä teemojen merkitystä Pentikäinen luonnehtii seuraavin sanoin:

\section{Professori Ilk.ka Nïniluoto ehdotti Karbun kannoilla -näyttelyä Yliopiston museoon. Näyttelyn perusidea habmottui seminaarimatkalla Key Westissä. Se oli betkiä, jolloin olen kokenut olevani olennaisten asioiden ytimessä. Karbu tulee omassa elämässäni monta kertaa vastaan.}

Pentikäisen saama karhuprofessorin lempinimi onkin hyvin perusteltu. Lapin yliopiston rehtorin Mauri Ylä-Kotolan sanoin: "tuo Juha on sellainen joka katselee maailmaa karhun silmin.” Karhut työllistävät Pentikäistä myös eläkkeellä. Yksi eläkeajan suururakoista tulee olemaan karhueepoksen kokoaminen. Työllään hän haluaa osoittaa, ettei eepoksemme ole ainoastaan Lönnrotin ansiota. Ajatus eepoksesta syntyi PohjoisAmerikan eteläkärjessä Key Westissä 2000-luvun alussa. 


\section{Marjo Kovanen}

Sen jälkeen ajatus alkoi kyteä ja olen vähitellen alkanut kokoilemaan aineistoa.

Ympärillä on apuna noin puolen tusinan hengen vahviinen työryhmä.

Tämän raadin kanssa Pentikäinen pohtii eepokseen liittyviä kysymyksiä ja miettii ratkaisuja. Tässäkin tapauksessa tutkimus on pitkälle ryhmätyötä. Projektin aikatauluun Pentikäinen suhtautuu samalla kiireettömyydellä kuin muutenkin eläkepäiviensä viettoon.

Pentikäinen kertoo kulkeneensa karhun kannoilla lapsesta saakka. Selvänä on säilynyt muisto lapsuudenmaisemien karhunkallohongasta: "Tämä karhuteema on aika mielenkiintoinen asia, koen että palaan juurilleni." Rantsilassa vuonna 1940 syntyneelle Pentikäiselle lapsuuden kokemukset ja muistot ovatkin viitoittaneet tutkijan uran reittejä:

Muistan asioita kaksivnotiaasta saakka, minulla on selvä muistikuva sodasta palanneesta isästä ja bänen saappaistaan. Muistan myös pappina toimineen isäni työtehtävät, kuolinviestien viennit ja lukemattomat hautaan siunaamiset.

Myös karhunkallopetäjä on jäänyt lapsuudesta vahvasti mieleen. Pentikäisen tutkimusaiheet ja kiinnostuksen kohteet siis pitkälti kumpuavat lapsuuden kokemuksista:

\section{Huomaan palanneeni jatkuvasti nä̈hin aiheisiin. Tutkimuksen kobteet tulevat paljolti lapsundesta. Yksi on kuolema, toinen karhu. Kontio tulee minua jatkuvasti vastaan.}

\section{ELÄMÄ ON LÖYTÖRETKI}

Yhtenä Karbun kannoilla -näyttelyn punaisena lankana kulkee kertomus kenttätyöstä: Millainen on kenttätyöprosessi? Mitä tutkija kokee ollessaan karhun kannoilla? Miten hän tuottaa aineistosta tieteellistä tutkimusta? Juuri kenttätyö onkin Pentikäisen tutkimuksissa määräävä piirre ja tärkeä - ellei tärkein - osa tutkimusprosessia. Hänen tyttärensä Katja Hyry toteaa Juha Pentikäisen 60-vuotisjuhlakirjassa Ethnography is a Heavy Rite, että työ on kuulunut itsestään selvästi kaikkeen hänen isänsä olemiseen (Hyry 2000, 19). Harrastuksesta tuli Pentikäiselle työ, ja työkseen hän on saanut tehdä sitä mitä on halunnut:

Olennaista tutkijanidentiteetissäni on, että haluan mennä tutkimustyössä paikan päälle, ihmisten luo. Loputon uteliaisuns ja unden etsintä leimaavat tutkimustyötäni, voisi sanoa että elämä on löytöretki. Etnografinen uteliaisuus on määrittänyt uraani, koen että olen ollut kentällä koko ikäni, lapsesta saak.ka.

Lapsesta asti harrastamaansa kiertelyä ja ihmisiin tutustumista hän kutsuu "Pirttiakatemiaksi”, jonka kautta kenttätyöstä on tullut elämäntapa ja elämänmittainen matka, josta on lopulta tullut koko Pentikäisen perheen jaettu kokemus. 


\section{KARHUPROFESSORIN JÄÄHYVÄISET YLIOPISTOLLE}

Helsingin yliopiston professoriksi Pentikäinen tuli vuonna 1972 Yhdysvalloista, jossa hän on ollut vierailevana professorina kuudessa eri yliopistossa. Hän viihtyi uuden maailman akateemisissa piireissä hyvin, ja tärkeimmät yhteydet ovat säilyneet näihin päiviin. Yhdysvaltoihin suuntautuvasta yhteistyöstä huolimatta kansainvälisten yhteyksien pääsuunta on nykyään muualla:

Tällä hetkellä keskeisimmät kansainväliset ybteyteni ovat Italiaan, Ranskaan ja Venäjään, tietysti myös Japaniin ja Kiinaan. Yksi intresseistäni on suomalaisunden pohdinta, se on paljolti peräisin ulkomailla olemisesta ja ulkomaisista kontakteista.

Yksi rikekaus matkustelussa ja tieteenalojen välillä olemisessa, on että on tavannut byvin erilaisia tutkijoita muun muassa Margaret Meadin, Mircea Eliaden, Kurt Ranken ja Archer Taylorin. Elämässä on tärkeätä pitkäaikaiset ystäryyssubteet, näiden ibmisten kobtaaminen on ollut suuri onni ja ilo. Yksi haaveeni on, että alkaisin käsitellä joitakin näistä tarinoista, muistella kobtaamisia näiden ibanien ibmisten kanssa.

Todellisia kulttuurintutkimuksen suuruuksia tavannut ja tuntenut Pentikäinen nostaa joukosta yhden legendan ylitse muiden:

Uskontotieteellisesti sunntautunut Martti Haavio on ollut suurin innoittajani. Tunsin bänet kymmenen vuotta aika läbeisestikin, bän merkitsi minulle valtavan paljon. Ensimmäisen kerran vierailin Haavion kodissa fuksivnonna. Martti Haavio itse asiassa neuvoi, että orientoituisin tieteelliselle uralle armeijasta palattuani.

Akateemisen aherruksensa Pentikäinen aloitti Helsingin yliopiston kansatieteen ja kansanrunouden peruskursseilla, luennoilla ja seminaareissa:

Kansanrunoudentutkimukseen kuului sïhen aikaan harjoitustyö approbaturia varten, jonka aiheena olivat eroottiset arvoitukset. Nauratti niitä lukiessa ja kirjoittaessa.

Myös Matti Kuusella on merkittävä sija Juha Pentikäisen tutkijan uran alkuvaiheessa. Hänen kauttaan nuori opiskelija sai muun muassa tulkin ja valokuvaajan tehtäviä:

Tieteen kieli oli tuolloin saksa, siksi oppaaksi tarvittiin englantia opiskeleva poika. Matti Kunsi pyysikin sitten minua oppaaksi Archer Taylorin suomenvierailulle kysyen "Kiinnostaako tämä herra ylioppilasta?" Kiersin kahden viikon aikana kaikeki Helsingin folkloristi-ja kansatieteilijäkodit. Tästä tuli tapa. Aina kun tuli joku kansainvälinen vierailija, esimerkiksi Linda Dégh, pääsin oppaaksi. Myös perbeiden tunteminen benkilökobtaisesti oli tärkeää. Tunsin esimerkiksi Kunsen perbeen ja byvin Haavion perbeen. 


\section{Marjo Kovanen}

Graduvaiheessa Kuusen kanssa saman kadun varrella asunut Pentikäinen käveli monta kertaa Hietaniemen hautausmaan ympäri professorin kanssa:

Jokaiselle kierroksella oli aina jokin maestron valitsema teema. Kerran pubuimme epiikasta, sen vanbimmista kerrostumista. Kunsi epä̈li niiden olevan shamanistisia. Muistan aina kun bän sanoi: "Ne kuullaksesi sinun on mentävä Siperian shamaanien nuotiotulille."

\section{KoHTALON NAINEN}

Vuonna 1971 julkaistu Marina Takalon uskonto on klassikko, jota voisi pitää käänteentekevänä tutkimuksena folkloristiikassa. Se avasi tutkimukseen yhden ihmisen tutkimuksen väylän. Myös Juha Pentikäisen elämälle ja uralle tällä tutkimuksella ja sen kohteena olevalla karjalaisnaisella on ollut valtava merkitys: "Marina Takalosta tuli minun kohtaloni nainen."

Pentikäinen kokee onnenpotkuksi sen, että aikoinaan ylipäätään sai tutkimukselle valtakirjan:

Yhden ibmisen tutkimusta ei pidetty folkloristisena ongelmana. Myös vertailevan aineiston puuttuminen aibeutti ongelmia byväksyttäryyden subteen. Tutkimus siirtyi ja sïrtyi. Olen onnellinen, että tein kenttätyötä kuusi vuotta ilman tutkimussunnnitelmaa. Tutkimussunnnitelman tein vasta 1966. Takalo tuli luokseni Turkunn ja tein tavallaan koko työn undestaan. Olin tutkijan lisäksi ikään kuin ystävä, kunlija ja kuuntelija. Verrattain pian minulle hahmottui, mitä muisti ja maisemamuisti ovat. "Oral memory" -käsite sai konkreettisen ilmiasun. Englanninkielisen version jälkeen homma jatkui 70-luvulla.

Jouduin heti tilille nimen uskonnosta: "Eibän se mikä̈̈n uskonto ole, sebän on pakanuus." Minua ei kiinnostanut uskonto dogmaattisena vaan ibmisen sisäisenä mielenmaisemana. Olen tyytyväinen, etten vaibtanut nimeä neuvoista buolimatta. Uskonto on uskonto pienellä u:lla, on tärkeää että termi läytyy ihmisen pubeesta eikeä tieteellisestä liturgiasta. Pitkä työskentely Marina Takalon kanssa opetti minulle, mitä uskonto on ja miten uskontoa käsitellään. Malli hahmottui 1970-luvun alussa. Loimme kaksi linjaa: historiallisen ja lingvistis-fenomenologisen linjan. Mukana oli vahvasti myösylilaitoksinen kenttätutkimuksen näkökulma. 10 vuoden aika fuksipojasta Takalon haudalle... Sinä aikana minun elämäntehtäväni hahmottui. Pitkän työn kokemuksen kautta kenttätyöstä on tullut periaate, joka määrittää lähes kaikkia tö̈täni.

Marina Takaloa muistetaan erityisesti vuonna 2010 hänen juhlavuotenaan. Osana juhlavuoden tapahtumia järjestetään Vienan tie -seminaari sekä näyttely Kuusamotalossa. Juhlavuoden kohokohdaksi nousee varmasti Helsingissä esitettävä Takalo-ooppera. 


\title{
KARHUPROFESSORIN JÄÄHYVÄISET YLIOPISTOLLE
}

Olen kokoamassa näyttelyä, ja Suomalaisen Kirjallisunden Seura julkaisee Marina Takalon uskonnosta unden laitoksen, joka ilmestyy myös englanniksi sekä ilmeisesti myös ranskaksi. Aion kuunnella kaikki nauhat vielä kertaalleen undestaan.

Marina Takalo ei ole ollut Juha Pentikäiselle kuitenkaan pelkkä tutkimuskohde vaan myös läheinen ystävä.

\begin{abstract}
Meistä tuli ystävät, Takaloiden perheystävät. Siitä on tullut elämänikä̈nen ystävyys, saan huomautuksen, jos en jokaiselta ulkomaanmatkalta lähetä korttia tai obi mennessä käy kylässä. Toki haluankin käydä. Ybteydenpito on luonnollista, Marina Takalo on meidän perheessämme tärkeä, bänbän asuikin meillä. Olin myös laskemassa seppelettä Marinan haudalle vnonna 1970.

Hänen kauttaan opin lähestymään suullisen muistitiedon problematiik.kaa ja kysymystä siitä, mitä kuolema ja kohtalo ovat.
\end{abstract}

\section{AKateemiset muUtoksen tUUlet PUhaltavat}

Juha Pentikäinen oli jo nuorena opiskelijana Helsingissä monessa mukana, lukuisia ylioppilaskorporaatioita myöten. Tohtoriksi hän väitteli vuonna 1968, Ilmar Talven toimiessa kustoksena. Varsinaisen akateemisen uransa hän aloitti Turusta Lauri Hongon assistenttina.

Akateemisessa ilmapiirissä hän näkee joitakin muutoksia tapahtuneen vuosien myötä. Hieman haikeana hän muistelee aikanaan hyvinkin vilkasta tieteidenvälisyyttä ja harmittelee kansallisten tieteiden läheisen yhteyden haihtumista.

\section{Castrenianum yliopiston yläkerrassa oli sellainen pybättö,jossa oli kansallisia tieteitä rivissä. Kaikki sanakirjat ja toimitukset olivat siellä, siellä olivat myös Haavio, Vilkuna ja munt. Kaikkei ne tieteenalat, jotka jatkoivat Castrénin perintö̈, olivat saman käytävän varrella.}

Opiskelijanuorukainen jäi Helsingin opintojensa pariin juuri tuon Castrénin henkistä perintöä hehkuvan ilmapiirin innoittamana, vaikka hänellä ei kovin selkeää päämäärää valmistumisen suhteen ollutkaan. Yksi konkreettinen ero Pentikäisen opiskeluaikojen ja nykyisen yliopistomaailman välillä on teitittelyperinteen katoaminen:

Matti Kunsikin teki sinunkaupat vasta kandintutkinnon jälkeen, naisopiskelijoita bän sinutteli vasta maistereina. Minua paheksuttiin, kun sinuttelin naisoppilaita.

Kuusikymmenluvun kansanrunouden tutkimus poikkesi aika lailla nykypäivän folkloristiikasta. Arkistovetoinen tutkimus vieroksui kenttätutkimusta ja piti tiukasti kiinni omasta reviiristään. 


\title{
Marjo Kovanen
}

\begin{abstract}
Sïhen aikaan folk:loristiik.ka oli genreorientoitunutta. Kenttätutkimuksesta alettiin pubua yleisesti vasta 1965 Vöyrin pohjoismaisessa kenttätyöseminaarissa. Olimme nuoria vihaisia miehiä, meitä ärsytti perinnäisyys ja tieteiden väliset tiukat rajat. Kansatieteessä hallitsi esinetutkimus, folkloristiikassa genretutkimus ja nïn edelleen. Minua kiinnosti kentälle lähtiessäni ibminen, se oli kimmoke kenttätutkimukseen. Minua ärsytti tiukeka genreluokittelu. Koin kiusalliseksi tebdä tink.kaa genretutkimusta. Ei ibmisellä ole genrejä, ne eivät vastaa ibmisen ajattelua. Tyylipubtaiden genrejen etsintä ei minua kiinnostanut.
\end{abstract}

Tieteenalan taantumuksellisuudesta huolimatta Pentikäinen sai innoitusta ja tukea valitsemalleen tielle ja löysi kenttätutkimuksen omaksi menetelmäkseen:

Kun tulin Suomalaisen Kirjallisuuden Seuran kansanrunousarkistolle amanuenssiksi vuonna 1961, arkiston jobtaja Lauri Simonsunri toi valittavaksi laatikoita, joista valitsin kansanuskon, koska se oli mielestäni kaikekein vähiten tutkittu. Simonsuuri oli minulle byvin läheinen ibminen, kuten oli Jouko Hautalakin.

Silloin, kun tulin Helsinkiin, pubuttiin kansanperinteen keruusta, keruntyöstä. Ensimmäisenä fuksivuonna en saanut kenttätutkimukseen apurahaa, koska minulla ei ollut kokemusta. Sain kuitenkin nauhoja ja magnetofonin. "Herra ylioppilas, tässä on kaksi laatikkoo, mutta säästäkeää nauboja.” Nauboista oli tarkoitus tebdä esityksiäja munta sellaista. Niitä tehtiin tuotantoa varten ja kaik.ki "ylimääräinen" leikattiin pois. Mutta minä pystyin pelastamaan naubat jobtuen siitä, että olin töissä kansanrunousarkistossa.

Uskoa tieteenalojemme tulevaisuuteen Pentikäiseltä löytyy viimeaikojen huolestuttavasta kehityksestä huolimatta:

En usko, että buonosti käy, kyllä me tarvitsemme suomalaisen perinteen tuntemusta, joka vain meillä on. Painoarvo oman perinteen ja kulttuurin tuntemisella on EU:ssa suuri. Vähemmistöjen ja kansallisen identiteetin tutkimus todennäkö̈sesti vain kasvattaa merkitystään.

Kannattaisi pitää huolta oman vahvan perinteen ja tutkimusperinteen, juuri meidän identiteettimme ja historiamme tutkimuksesta. Tällä tulisi olla tutkimuksessa suuri painoarvo.

Tutkimuksen ytimen ei pitäisi olla muodikekaan sunntauksen varassa, jolloin se voi jo kymmenen vuoden kuluttua olla arvoton. Perustuminen vahvaan aineistoon antaa tutkimukselle sen pysyvän arvon.

Näiden evästysten lisäksi eläkkeelle jäävä professori neuvoo tieteenaloja oppimaan toisiltaan ja muistamaan M. A. Castrénin perinnön.

Juha Pentikäinen haluaa vielä tiedottaa kaikille Elorelaisille tärkeästä tapahtumasta Cambridgen yliopistossa vuonna 2011. Kyseessä on juhlaseminaari, jonka yhteydessä järjestetään yhteistä pohjoista perinnettä korostava Under the Great Bear-tapahtuma. Kyseessä on brittiläisen antropologian ja suomalaisen pohjoisen etnografian 
100-vuotiskohtaamisen juhlaseminaari. Vuonna 1911 Kai Donner aloitti opintonsa ennen kuin lähti Siperiaan Sir James Frazerin fonografin kanssa.

Kansallista kulttuuria vaaliva ja kansainvälistä yhteistyötä korostava Pentikäinen huomauttaa:

Tämä merkittävä tilaisuus olisi erittäin tärkeää tiedostaa Suomessa, se on loistava tilaisuus keskustella kansainvälisellä areenalla.

\section{KiRJallisuUs}

HYRY, KATJA 2000. "Luonnos tutkijan kuvaksi." - Holm, Nils G. (toim.), Ethnograpby is a heavy rite. Studies of comparative religion in honour of Juba Pentikä̈nen. Åbo: Åbo Akademi.

Filosofian maisteri Marjo Kovanen on jatko-opiskelija Jyväskylän yliopistossa 